\title{
Cationic Oligomerization of Epichlorohydrin
}

\author{
Koichi Iто,* Noriyuki Usami, and Yuya Yamashita \\ Department of Synthetic Chemistry, Faculty of Engineering, \\ Nagoya University, Furo-cho, Chikusa-ku, Nagoya 464, Japan.
}

(Received June 16, 1978)

\begin{abstract}
KEY WORDS Cationic Oligomerization / Cyclic Oligomer / Epichlorohydrin / Oligomer / Dimer / Tetramer /
\end{abstract}

Cationic polymerization of oxiranes is known to produce a considerable amount of cyclic oligomers $^{1-3}$ as well as high polymers. Recently, much attention have been given to these oligomers in connection with the direct synthesis of crown ether. ${ }^{4}$ However, it is not known whether oligomerization conditions can be controlled to give specific cyclic oligomers. In order to investigate the factors influencing cyclic oligomer formation, cationic oligomerization of epichlorohydrin (ECH) under various conditions was carried out in this study.

\section{EXPERIMENTAL}

$\mathrm{ECH}$ was distilled over calcium hydride. Boron trifluoride diethyletherate $\left(\mathrm{BF}_{3} \mathrm{OEt}_{2}\right)$ was distilled under a nitrogen atmosphere and stannic chloride $\left(\mathrm{SnCl}_{4}\right)$, and trifluoromethanesulfonic acid $\left(\mathrm{CF}_{3} \mathrm{SO}_{3} \mathrm{H}\right)$ were used as supplied. Solvents were purified by conventional methods. The oligomerization reaction was carried out under a nitrogen atomosphere by the dropwise addition of the monomer to the initiator solution while being stirred and cooled in order to control the vigorous exothermic reaction. The overall monomer concentration was 0.20 to $2.9 \mathrm{~mol} / l$ and that of initiator was about $50 \mathrm{mmol} / l$. The reaction was terminated with a $5-\%$ aqueous $\mathrm{NaOH}$ solution and the product was then extracted with ethyl ether. Viscous products were obtained after evaporating off the solvents under reduced pressure. Product distribution was determined by GPC, Toyo Soda HLC 802UR equipped with 4 feet of $\mathrm{G} 2000 \mathrm{H} 8$ (nominal porosity $2.5 \times 10^{2} \AA$
TP/F 8000) columns eluted with $\mathrm{CHCl}_{3}$. The peak position and intensity (area) were calibrated using the cyclic oligomers which had been isolated, as will be described later. The tetramer peak intensity per unit weight relative to dimer was 1.38 , and that of trimer was assumed to be equal to the dimer; those of the heptamer and the higher oligomers were assumed to be equal to the tetramer. Relative error involved in determining the amounts of the products is believed to be within $\pm 20 \%$. The dependence on conversion was scarcely observable. During distillation, needle-like crystal sublimed at $60 / 0.15 \mathrm{mmHg}$ and was identified as the cyclic dimer: $\mathrm{mp}$ (recrystallized from toluene) 108.9-110.7 ${ }^{\circ} \mathrm{C} \quad$ (lit. $^{5} \quad 109-110^{\circ} \mathrm{C}$ ); ${ }^{1} \mathrm{H}$ NMR $\left(\mathrm{CDCl}_{3}\right) \delta 3.3-4.2(\mathrm{~m}) ;{ }^{13} \mathrm{C} \mathrm{NMR}\left(\mathrm{CDCl}_{3}, \delta \mathrm{ppm}\right.$ from TMS) 42.74, 69.05, 74.01; mass spectrum m/e 184, 186, 188. Anal. Calcd for $\left(\mathrm{C}_{3} \mathrm{H}_{5} \mathrm{ClO}\right)_{n}$ : C, 38.94; H, 5.45; Cl, 38.32. Found: C, 38.92; $\mathrm{H}, 5.21 ; \mathrm{Cl}, 37.28$. The fraction at $185-195 /$ $0.5 \mathrm{mmHg}$ (lit. $^{2} 195-205 / 1 \mathrm{mmHg}$ ), a viscous liquid, was diluted with toluene and cooled overnight. The needle-like crystal formed was identified as the cyclic tetramer I: $\mathrm{mp}$ (recrystallized from toluene) $135.2-136.6^{\circ} \mathrm{C}$ (lit. ${ }^{2,6} 133-136^{\circ} \mathrm{C}, 136-$ $\left.138^{\circ} \mathrm{C}\right) ;{ }^{1} \mathrm{H} \mathrm{NMR}\left(\mathrm{CDCl}_{3}\right) \quad \delta 3.3-4.2(\mathrm{~m}) ;{ }^{13} \mathrm{C}$ NMR $\left(\mathrm{CDCl}_{3}, \delta \mathrm{ppm}\right.$ from TMS) 43.45, 72.02, 80.56; mass spectrum $m / e 368,376$, etc. Anal. Found: C, 38.75; H, 5.22: Cl, 36.99. The simplicity of the ${ }^{13} \mathrm{C}$-NMR peaks suggests that tetramer I has a configuration like that either of all trans or all cis. Later another crystal, formed from the same fraction, was identified as cyclic tetramer II which has not yet been reported on: mp (recrystallized from toluene) $150.9-152.1^{\circ} \mathrm{C} ;{ }^{1} \mathrm{H}$ NMR 
$\left(\mathrm{CDCl}_{3}\right) \delta 3.3-4.2(\mathrm{~m}) ;{ }^{13} \mathrm{C} \mathrm{NMR}\left(\mathrm{CDCl}_{3}, \delta \mathrm{ppm}\right.$ from TMS) 42.98, 43.17, 70.24, 71.75, 79.96, 80.28; mass spectrum $m / e$ 368, 376, etc. Anal. Found: C, 38.90; H, 5.22; Cl, 37.04. The multiplicity of the peaks suggests the tetramer II to be a irregular stereochemical isomer such as cis-cis-cistrans. The ${ }^{1} \mathrm{H}$ NMR or IR spectra of each fraction revealed the absence of any characteristic end groups (carbonyl, hydroxyl, double bonds) which could possibly be present in linear chains.

\section{RESULTS AND DISCUSSION}

The cationic oligomerization of ECH was conducted under a variety of conditions and the product distribution was analyzed by GPC. Figure 1 shows the typical GPC chromatograms and the results are summarized in Table I. The GPC chromatograms showed products having a rather wide range of molecular weight involving principally the dimer, tetramer and pentamer. Only a little trimer could be detected.

The product distribution was critically dependent upon the initiators employed. With $\mathrm{BF}_{3^{-}}$ $\mathrm{OEt}_{2}$ as an initiator, the product had molecular weights of 200 to 2000 . On the other hand, with $\mathrm{SnCl}_{4}$, there were considerably more high molecular weight oligomers. A low molecular weight oligomer formation would not be typical of Lewis acid initiators. $\mathrm{CF}_{3} \mathrm{SO}_{3} \mathrm{H}$ was considerably ef-

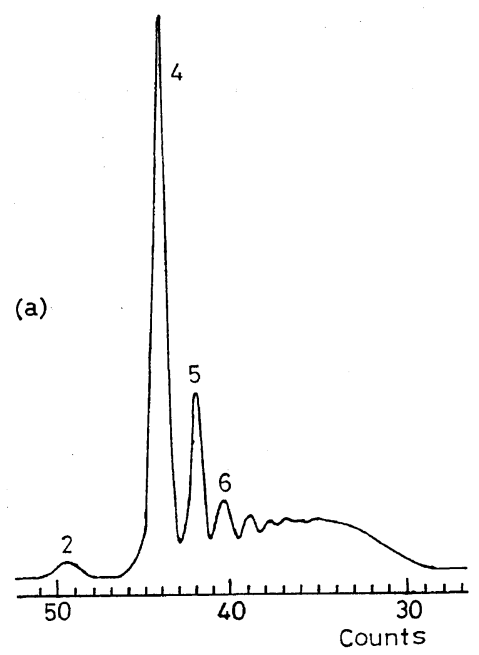

(b)

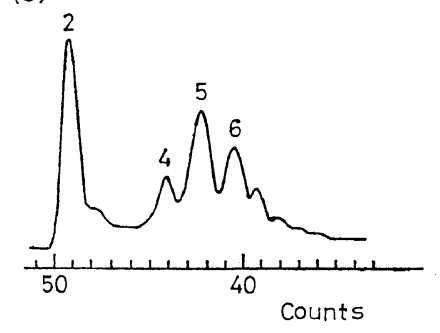

Figure 1. Typical GPC chromatograms of the products of ECH oligomerization in 1,2-dichloroethane at $\sim 5^{\circ} \mathrm{C}$. Initiator: (a) $\mathrm{BF}_{3} \mathrm{OEt}_{2}$; (b) $\mathrm{CF}_{3} \mathrm{SO}_{3} \mathrm{H}$.

Table I. The product distribution of ECH oligomerization in various systems ${ }^{\mathrm{a}}$

\begin{tabular}{|c|c|c|c|c|c|c|c|c|c|c|c|c|}
\hline & \multirow{2}{*}{ Initiator } & \multirow{2}{*}{ Solvent } & \multirow{2}{*}{$\begin{array}{l}{[\mathrm{M}]_{0}{ }^{\mathrm{c}}} \\
\mathrm{mol} / / l\end{array}$} & \multirow{2}{*}{$\begin{array}{c}{[\mathrm{I}]_{0}{ }^{\mathrm{d}},} \\
\mathrm{mmol} / l\end{array}$} & \multirow{2}{*}{$\underset{\mathrm{h}}{\text { Time, }}$} & \multirow{2}{*}{$\begin{array}{c}\text { Yield, } \\
\%\end{array}$} & \multicolumn{6}{|c|}{ Product distribution ${ }^{\mathrm{b}}, \mathrm{wt} \%$} \\
\hline & & & & & & & $n=2$ & $n=3$ & $n=4$ & $n=5$ & $n=6$ & $n \geqq 7$ \\
\hline A-1 & $\mathrm{BF}_{3} \mathrm{OEt}_{2}$ & 1,2-Dichloroethane & 2.2 & 50 & 4.0 & 98 & 2 & 0 & 43 & 14 & 6 & 35 \\
\hline$A-2$ & & Dioxane & 2.1 & 50 & 4.0 & 11 & 18 & 1 & 4 & 22 & 20 & 35 \\
\hline A-3 & & Toluene & 1.8 & 50 & 4.0 & 88 & 1 & 0 & 26 & 12 & 7 & 54 \\
\hline$A-4$ & & Ethyl ether & 1.8 & 50 & 4.0 & 5 & 3 & 2 & 13 & 22 & 19 & 41 \\
\hline$A-5$ & & 1,2-Dimethoxyethane & 1.8 & 50 & 4.0 & 19 & 5 & 0 & 60 & 31 & 4 & 0 \\
\hline A-6 & & 1,2-Dichloroethane & 0.27 & 50 & 4.0 & 30 & 3 & 1 & 52 & 15 & 12 & 17 \\
\hline A-7 & & Ethyl ether & 0.20 & 50 & 4.0 & 3 & 7 & 4 & 40 & 26 & 11 & 21 \\
\hline B-1 & $\mathrm{SnCl}_{4}$ & 1,2-Dichloroethane & 2.7 & 50 & 3.0 & 75 & 5 & 0 & 9 & 11 & 7 & 68 \\
\hline B-2 & & Dioxane & 2.5 & 63 & 2.5 & 50 & 15 & 0 & 5 & 6 & 6 & 68 \\
\hline B-3 & & Toluene & 1.9 & 43 & 23.5 & 73 & 9 & 0 & 12 & 12 & 11 & 56 \\
\hline $\mathrm{C}-1$ & $\mathrm{CF}_{3} \mathrm{SO}_{3} \mathrm{H}$ & 1,2-Dichloroethane & 2.5 & 57 & 7.0 & 2 & 45 & 0 & 8 & 21 & 16 & 10 \\
\hline $\mathrm{C}-2$ & & Dioxane & 2.9 & 77 & 23.0 & 12 & 32 & 0 & 13 & 17 & 14 & 24 \\
\hline
\end{tabular}

a Temp., $\sim 5^{\circ} \mathrm{C}$ (dioxane systems, $\sim 15^{\circ} \mathrm{C}$ ).

b Oligomer distribution by GPC. $n,(\mathrm{ECH})_{n}$.

c Overall monomer concentration.

d Overall initiator concentration. 
fective in this respect, but with low conversion. In this system, low molecular weight oligomers, especially the dimer, were the main product, regardless of the solvent. This result may be explained by considering that the propagation species in this system may be a less reactive ester and unsusceptible to solvent.

The solvent effect in the product distribution was observed with $\mathrm{BF}_{3} \mathrm{OEt}_{2}$. In 1, 2-dichloroethane or toluene, the reaction was rapid and the molecular weight distribution was wide. It was noted that as much as $40 \%$ of the tetramer was obtained in the system with $\mathrm{BF}_{3} \mathrm{OEt}_{2}$ in 1, 2dichloroethane $(\mathrm{A}-1)$. With ethereal solvents, the reaction was slow as might be expected. By employing highly basic 1, 2-dimethoxyethane as a solvent, low molecular weight oligomers $(200-600)$, especially tetramer and pentamer were formed almost exclusively. High basicity of etheral solvents is expected to suppress the propagation reaction but to promote a back-biting reaction to produce low molecular weight cyclic oligomers.

Low monomer concentration favoured low molecular weight oligomer formation as is shown in the experiment $\mathrm{A}-1$ and $\mathrm{A}-6, \mathrm{~A}-4$ and $\mathrm{A}-7$ in Table I. This result, together with the formation of the normal cyclic oligomers, suggests the following scheme with the usual oxonium-ion propagation $\left(S_{N} 2\right)$ accompanied by the back-biting reaction.

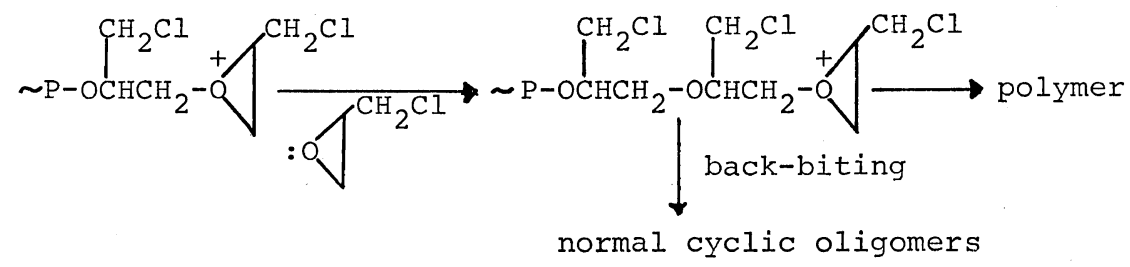

This is in contrast with the case of styrene oxide or isobutylene oxide ${ }^{7}$ which involves a carbonium ion intermediate isomerized through a hydride transfer $\left(S_{N} 1\right)$ to give oligomers with acetal linkage.

\section{REFERENCES}

1. E. J. Goethals, Adv. Polym. Sci., 23, 104 (1977).

2. R. J. Kern, J. Org. Chem., 33, 388 (1968).

3. R. J. Katnik, and J. Schaefer, J. Org. Chem., 33,

384 (1968).

4. S. Kobayashi, K. Morikawa, and T. Saegusa, Macromolecules, 8, 952 (1975).

5. J. D. McClure, U. S. Patent 3,140,296 (Cl. 260340.6) (1963); Chem. Abstr., 61, 8318d (1964).

6. M.G. Zelenskaya, F.L. Kolodkin, F.P. Sidel'kovskaya, and V. A. Ponomarenko, Izv. Akad. Nauk SSSR, Ser. Khim, 5, 1105-1112 (1968); Chem. Abstr., 69, 36670g (1968).

7. Y. Yamashita, K. Iwao, and K. Ito, to be published. 